\title{
Making the Most of School Arts Education Partnerships
}

\author{
Christine Hall ${ }^{1}$ (D) Patricia Thomson $^{1}$ (D)
}

Published online: 19 April 2021

(C) The Author(s) 2020

Keywords School arts partnerships · Arts broker teachers · Cultural brokerage

\section{Introduction}

Partnership is a slippery word, a nuanced and often ambiguous concept. In relation to schools, partnerships tend to be warmly welcomed and rather poorly defined. In theory, loosely defined partnerships are tantalising, seeming to offer potential for engagement in a wide range of activities that serve a variety of purposes. But many school partnerships begin with a bang and a bit of a splash and fade away with barely a whimper.

For many years now, we've been interested in partnerships between schools, arts and cultural organisations and artists. Seventeen years ago, we documented the ways in which enthusiasm for an arts partnership in one English primary school waned as the gulf between the artist's and the headteacher's worldviews was gradually revealed (Thomson et al. 2006). Later, we worked closely with Creative Partnerships, an ambitious national programme intended to promote creativity in schools in England and Wales (Thomson et al. 2009). Recognising that there were obstacles in the way of building sustainable partnerships between schools and the creative sector, Creative Partnerships [CP] devised a new role - the 'creative agent' - whose job was about liaison, facilitation and clarification of aims and responsibilities (Sefton-Green 2011). The definition of the creative agent role drew attention to the work involved in build partnerships between schools and the cultural sector.

At its best, we had seen in the CP work evidence of the development of school arts partnerships that were reciprocal, educationally ambitious and clearly defined (Hall and

Christine Hall

christine.hall1@nottingham.ac.uk

Patricia Thomson

Patricia.Thomson@nottingham.ac.uk

1 University of Nottingham, University Park, Nottingham, UK
Thomson 2017). When, after a change of government, CP was terminated, we wanted to explore how these partnerships could continue to flourish. This was a research agenda we pursued in partnership with the Royal Shakespeare Company [RSC] and Tate, internationally outstanding arts institutions both strongly committed to working closely with schools.

In this article we discuss the implications of findings from this collaborative research. First, though, we consider some key issues raised by other commentators.

\section{School arts partnerships: Purposes and problems}

School partnerships are invoked for a variety of purposes, including to create or cement notions of community, to promote academic achievement, to fill gaps and meet students' basic needs, to improve the flow of financial or other resources and to contribute to righting social wrongs (Perkins 2015). They are also used to influence, to promote reform and sometimes to exert control (Burgos 2004; Popkewitz 2004).

This range of purposes is evident in the activities of school arts partnerships. Some, for example, are focussed primarily on access to theatres, galleries etc. and on civic engagement. Others involve projects related to specific subjects and sometimes exam syllabuses, or to more generalised encouragement of creativity, or to filling gaps in the school's curriculum where arts provision is squeezed. One-off performances and events create opportunities for creative sector workers to be employed in school, contribute to audience building for the arts and are often argued for in terms of enhancing the cultural capital of particular groups of pupils. Often, of course, the partnerships aim to meet several or all of these purposes, and to add others.

These are valuable initiatives. However, as school arts partnerships have proliferated, commentaries on how they function have drawn attention to potential - and actual - drawbacks inherent in some partnership models. In an article about arts 
partnerships in Canadian elementary schools, Hanley (2003) argues that, in the long term, partnerships can be deleterious to the quality of arts education. The possible damage, she argues, comes from the channelling of resources into the partnerships rather than investing them in specialist arts teaching and teachers. She worries about generalist primary school teachers losing confidence in teaching the arts, specialist arts teachers becoming isolated, arts education associations losing their power to influence. She points out that exposure to the arts does not in itself promote meaningful learning; that highquality arts education needs to be continuous, sequential and focussed on skill development and process. Partnership initiatives on the other hand are often one-off or short term and therefore fragmented, focused on performances or exhibitions as the main outcomes. The danger, Hanley says, is that these partnerships pass for arts education on the grounds that specialist teachers cannot be afforded, there are no qualified teachers available, or the staff does not include teachers competent to teach the arts. (p19). This is possible she argues because of the depreciation of the role of arts educators and a general willingness to denigrate teachers and teacher preparation programmes and accord them lower social status than artists and fine art education (p14).

In an insightful article about the Norwegian Cultural Rucksack programme, Christophersen (2013) analyses some of the ways in which this marginalisation and devaluing of teachers' work occurs, even in the context of a widely supported and admired national school arts programme. She observes a competent and experienced music teacher who had been told by a visiting professional musician not to interfere in the musical processes, but who nevertheless subtly facilitated the event to prevent the visiting musician's lack of experience with school children from becoming a real problem. When asked about this, the teacher said, "I offered to help him in the music room, but he said he didn't need it. But I help him anyway; I have to." (Christophersen 2013, p5).

Because of what Christophersen calls 'a perceived twosomeness between artists and students', the teachers sometimes feel redundant, or reduced to acting either as assistants to the visiting experts ('helpers') or as disciplinarians who keep order and intervene to ensure good manners ('guards'). The issue highlighted here is not, then, simply about a devaluing and under-utilising of the teacher's expertise but also a lack of clarity about the nature of the partnership. Who are the partners? As Christophersen puts it: 'A dyadic relation between artists and students may leave little room for teachers' (p8), an exclusion which diminishes the potential educational gains of the partnership and also weakens its sustainability.

Kenny et al., in a more recent study of six artist-teacher pairs in Ireland, also highlight the negative connotations of the teachers', in comparison to the artists', role (Kenny and Morrissey 2020). However, in this case the response was to 'disrupt the negative-positive binaries embedded in these categories' by using the partnership to encourage dialogic relationships that 'enabled the blurring of boundaries between the identity categories of teacher and artist' (p5). So the aim of these partnerships was, in part, to disturb and then blend aspects of the different partners' roles.

These studies raise important questions about the distinctiveness of the roles and the relative positions of the teachers and artists in school arts partnerships. They also beg the question of how - and perhaps whether - the partnerships offer direct educational benefit to students.

We move on now to outline the TALE research and explain how we think it throws light on some of these questions.

\section{The TALE project}

Tracking Arts Learning and Engagement was a three-year longitudinal research project funded by Arts Council England (TALE 2019). The research set out to investigate what teachers learn from deep engagement with cultural organisations; how teachers translate this learning into classroom pedagogies and what students gain from these learning experiences. It also explored what the RSC's and Tate's different partnership models offered teachers in terms of professional development and learning.

The research was conducted in a purposive sample of thirty secondary schools, including three special schools; the schools served a diversity of communities spread across different regions of England. Fifteen of the schools were nominated by the RSC and fifteen by Tate, on the basis of the longterm professional involvement of the school, or teachers from the school, in partnership activities with the company/gallery. We constructed the sample in this way because we wanted to explore sites where we assumed (from their prior engagement with the RSC or Tate) there would be at least a reasonable degree of commitment to arts and cultural education, supported by partnership relations with one or more cultural organisation.

We aimed to follow 60 teachers over the three years, two per school; in the event, the final total of teacher participants was higher (80), due to staff turnover. Because of the nature of the arts organisations involved, most of the teachers in our sample were teachers of art, photography, drama, performing arts or English. Each year we visited each of the schools for between one and three days to interview the teachers, examine documents, take photographs and observe teaching. We followed up different themes in these interviews, depending on the issues that were arising from our ongoing analysis, building on and revisiting issues that had been raised in previous interviews.

We also tracked students across the three years of the project in each of the 30 schools. Each year we recorded 
interviews with focus groups of students in years 10-13 (ages 14-18) who were studying the arts. Through these focus groups, we spoke to almost 1500 students in years 10-13. Also, in year 2 of the project, we conducted a survey of students in years 10-13 in the sample schools to find out about the general level of students' engagement with arts and cultural activities in and out of school. The survey replicates some items from an annual government survey, which has allowed us to compare students in the TALE schools against a representative national sample. In the end, 4477 questionnaires were completed and analysed.

We draw on findings from across these datasets in the analysis that follows.

\section{Teachers as arts brokers}

Overwhelmingly, the students we interviewed talked about how arts subjects helped them develop their knowledge and critical thinking skills; their enjoyment of the subjects they were taking and the contribution they made to their sense of personal wellbeing. They talked about the ways in which the arts related to who they were, how they wanted to be and the things they might do in the future. Some intended to try to pursue the arts further through formal education and/or careers. Many emphasised the point that they saw the arts as being connected to the ways they wanted to live their lives (see, for e.g., the quotation at 4 below). These students saw their arts practice as something they planned to keep going, alongside whatever paid work they did.

There were six main themes that came from what students told us about why studying the arts was important to them. Table 1 lists these themes and illustrates them with quotations from different students.

We were struck by how frequently we were told by students that their arts teachers were different and that they taught differently. Overwhelmingly, students said they liked and appreciated these differences. Of course, individual practice varied between teachers and across different arts disciplines. Nevertheless, very clear and coherent themes emerged from the student interviews and these themes were confirmed in the teacher interviews and by our own observations. The differences, according to the students, were that in their arts subjects they were allowed to work more independently, to do research, to explore questions that they were interested in, to develop skills and to realise ambitious ideas.

We were interested in what made the students feel this way, since many teachers across the range of subjects would say they were committed to these same approaches to students' learning. One conclusion that we reached, based on our observations and analysis of the interviews and documents, was that in both the performing and visual arts teachers tended to approach students as 'artists'. Drama teachers used process drama, rehearsal room and ensemble pedagogies (O'Neill 1995; Neelands 2009). Art teachers worked through whole class workshops and small group or individual projects to encourage intellectual and disciplinary skills development (Hetland et al. 2007). Students were supported to take risks, to be responsible for deadlines, to exhibit and perform their work to real audiences. They were expected to engage in critical interpretation of their own and others' work. Executed well, this was highly skilled pedagogical work, deeply embedded in the signature pedagogies of the particular arts disciplines (Hall and Thomson 2016; Shulman 2005). To be successful, it required close engagement with the cultural interests of the students and their local contexts, and specialist knowledge of professional norms and practices within the discipline.

We knew from the rich autobiographical accounts in our teacher interview data that engagement in the arts - as practitioners, as audience, as critics and admirers - was a highly valued element in almost all of the teachers' personal identities. Generally, they had been interested, excited and moved by art works of various kinds throughout their lives; this had almost invariably been the basis of their personal decisions to become students, and then teachers, of arts subjects. As students, they had appreciated the same sense of autonomy and purpose that their own students were expressing to us now. Meaningful engagement with cultural organisations played an important part in maintaining this element of their identities: they were interested in the arts, wanted to keep abreast of new developments, saw cultural engagement as important to their social lives and the enjoyment of their leisure and family time. For some, the commitments of busy professional and family lives had reduced time and opportunities to express this aspect of their personal identity. These teachers particularly welcomed any opportunities to immerse themselves in the arts again and to re-connect with some of their earlier creative experiences.

From these data we concluded that what the students saw as different about their arts teachers related to what we call their cultural brokerage role. We see this as a distinctive educational role within schools, and one that is currently undervalued in training, in CPDL and in the structures and reward systems of schools. Our evidence suggests that 'arts broker teachers' actively link what goes on in the classroom to what the students do at home, and to artistic and cultural life more widely. In school this means approaching the class as a community of producers who work together to share, critique and debate ideas in a respectful and appreciative manner. It also means setting ambitious projects that take time, then scaffolding teaching so that students can develop understanding, make and correct mistakes, rehearse ideas, build their confidence, work at home on what they have started in school.

Beyond the classroom - but highly relevant to what happens there - arts broker teachers see it as part of their work 
Table 1 Responses to focus group discussions with students about why the arts are important to them

$\begin{array}{ll}\text { Theme } & \text { Illustrative student comment }\end{array}$

1. They have more sense of agency and independence in arts lessons than in other lessons. They feel more free

2. They like the fact that there is no right or wrong in the arts

3. Arts lessons help them build self-belief and confidence

4. The arts produce a sense of well-being; they are a valve for releasing pressure

5. They think that studying the arts is demanding and they have to work hard

6. They think arts teachers are a bit different
"It's more laid back, free. They let you do your own thing. You're learning in the way you want to, not a strict way, 'oh you've got to do this or that'. They give you the guidelines of what you have to have completed by a certain point and they let you get on with it, instead of telling you every step of the way." (Y11)

"It allows you to be more experimental. In Drama, you have to try different ways of doing something until it works... In lots of subjects there's always one right answer you have to strive to get right, but Art is what you do and what you achieve." (Y10)

"Before, I was very confined and I used to stop myself from saying any of my ideas even though my head was bursting. Now I'm not so afraid. That's how I know I've progressed." (Y10)

"It's a form of relaxation for me. It's so cool that there are subjects like this that bridge the gap with real life." (Y12)

"You get people who say 'oh I wish I did drama' especially when they see how good we are and how much effort the whole department puts in. It's not just us, it's the teachers as well. They [other students and staff] were very surprised at how much we can do on our own and at what drama as a subject can do. Yeah, we do actually do work!" (Y12)

"Teachers in other subjects rely heavily on technology, on PowerPoints. The Drama teachers are talking to you from personal experience. It's better like that, it feels like they're talking to you from their own experience and addressing you personally." (Y10) to connect students to local artists, events and organisations. They do this by organising in-school and out-ofschool visits as part of their classroom programmes; they seek out opportunities for students to exhibit and perform their work for wider public audiences; where they can, they introduce and try to connect students to national institutions and organisations, and to arts workplaces. To do this, teachers need to find out about and value students' own cultures and interests; take a critical interest in the popular and everyday; look for opportunities to negotiate the curriculum to reflect students' individual interests. For the teachers in our sample this approach came quite naturally. They enjoyed engaging with the arts themselves, in their leisure time and in their professional lives. They were often part of local, regional or national arts networks. They were committed to continuing to learn about the arts and keen to share their knowledge and out-of-school experiences with their students, routinely talking about what they had seen and done and made and read. In these ways, arts broker teachers acted as role models for students, embodying and enacting what it means to be culturally engaged, creating an ongoing cultural conversation in the classroom. The Year 10 student's comment cited above - "The drama teachers are talking to you from personal experience. It's better like that, it feels like they're talking to you from their own experience and addressing you personally"- is typical of what hundreds of students told us.

Led by the students then, but also by the ambitions and values expressed by the teachers themselves and by our experience of observing arts teachers at close quarters over the three years of the research project, we came to the conclusion that the brokerage role of arts teachers is distinctive and highly generative in the classroom. However, what was also clear was that the distinctiveness of this cultural brokerage element of arts teachers' work was underestimated and often overlooked in the wider school. School managers often viewed out-of-school cultural visits as inconveniences or treats; budgets were set in ways that prohibited artists from visiting school; briefings on exam syllabuses were prioritised at the expense of discipline-based professional development for teachers.

All of which led us back to thinking about the potential of school arts partnerships.

\section{Two successful school arts partnerships}

The teachers in the TALE study worked in schools that had links with either the RSC or Tate. Some were in schools that had formal partnership agreements with the arts organisation, others had looser connections. Both arts organisations encouraged partners to visit, put on special events for them, produced teaching resources, etc. What was particularly notable about both though, was the primacy they gave to working directly with teachers.

While the partnership with RSC or Tate was of marginal or no importance to some of the teachers in the TALE sample, usually because they had not had the time to engage with it, 
most of the teachers valued the relationship very highly. Overwhelmingly, the interview data attests to the view that their experiences with the RSC and Tate offered teachers new ways of thinking about their work. The comments below are typical of many others:

"It was their training and CPD that changed my career." "For myself, it's definitely changed the way I teach. It has changed the way that I teach everything."

"It's been transformative in terms of my own practice." "They've reinvigorated me as a practitioner and given me confidence."

"At every point they challenged things that I have to do every day."

"We use it all. I think it has revolutionised my teaching and I think about it in a completely different way now."

The RSC and Tate models of working with teachers differ. Tate's focus is on individual teachers, who are offered the opportunity to engage in immersive experiences, either through a network, through single professional development events or through an intensive Summer School in the gallery. Through encounters with artists and artist-mediated materials, teachers are encouraged to experience, as learners, the pedagogical principles of open-ended, critical aesthetic inquiry. At the same time, they are supported to consider how they might teach in ways that encourage their pupils to question, explore, challenge, play and interpret.

The RSC has established a national network of schools. It offers teachers the chance to work alongside RSC professionals to learn about rehearsal room approaches to interpreting Shakespeare. Teachers are encouraged to learn about the work of actors and directors by getting out of their seats and using their bodies, minds and emotions to get to grips with the plays. Then, supported by RSC staff, they take these approaches and try them out in the classroom. The teachers receive ongoing support in developing local networks and in staging Shakespeare performances in their schools and community settings.

Although the organisations use different partnership models, in our analysis of their work with teachers we identified a set of characteristics that were common to both.

Underpinning both was a recognition and respect for the professionalism of both teachers and artists, whose professional spheres and identities were understood as distinct but complementary. There was no attempt to blur roles; it was assumed that each group had something to learn from the other. Both arts organisations offered immersive professional development experiences, which gave teachers the chance to understand the professional norms, practice and debates of the discipline they were teaching. These immersive experiences had both intellectual and embodied, physical and emotional, dimensions. There was time to develop focus and flow, to tackle problems and allow ideas to grow: conditions that replicated the learning environments the teachers aimed to set up in their own classrooms. Artists recognised the teachers' pedagogical expertise; they acknowledged the professional requirements of teachers' day to day work, skills and knowledge and the specificity of teachers' commitments to the communities they served. One teacher commented that it was "the most inspirational training that I've ever experienced because you put yourself in the position of the student, so you are fully immersed in the activities but, at the same time, reflecting as a teacher."

The teachers were encouraged to work with one another, as well as to build cross-professional collaborations. There was careful attention to group dynamics, but there was also an investment in each individual. Relationships were nurtured; past experiences and other identities were recognised; there were clear expectations that the relationship was two-way and, ideally, would be sustained. Individual teachers told us they felt they had a personal relationship with the arts organisation and they valued this greatly. These relationships were underpinned and sustained by clear agreements about the commitment of time and resources from each of the partners so that expectations were shared.

Conclusions Fundamentally, we conclude that these school arts partnerships work well because they take proper account of the importance of teachers' work. They are educational partnerships; enhancing pedagogy and disciplinary knowledge are at their heart and define their purpose. They avoid the pitfalls identified by Hanley, Christophersen et al., recognising instead the pivotal role that arts teachers can play in brokering cultural opportunities and ideas to the young people they teach.

Although some teachers also have identities as artists, and some artists are also teachers, the roles are distinct. An arts teacher's role is to introduce students to a range of forms and genres and technologies; to help them develop skills and creativity, find meaningful forms of self-expression and debate ideas and different points of view. But it is also to help students make cultural connections out from and back into their homes and, more widely, to help them become active cultural citizens. Effective school arts partnerships explicitly support and enhance this brokerage element of arts teachers' role. They give teachers - and through them, pupils - privileged access to arts venues, skilled professionals and high quality resources. They immerse teachers in arts learning at their own level and then encourage joint work on how resources can be made meaningful to school students. For many of the teachers the experience also allows them to re-engage with their own earlier disciplinary identities, as students of the arts; for all of them there are connections to their out of school identities and interests in the arts. 
If young people have a right to culture (United Nations n.d.) and to be educated to become cultural citizens (Thomson et al. 2019), all students - not just those who attend elite or privileged schools - need arts and cultural education in school. The playing field is not level for all students and families. School arts partnerships, properly constituted between teachers and arts organisations, with clear educational aims, can and should play an important part in this work.

Open Access This article is licensed under a Creative Commons Attribution 4.0 International License, which permits use, sharing, adaptation, distribution and reproduction in any medium or format, as long as you give appropriate credit to the original author(s) and the source, provide a link to the Creative Commons licence, and indicate if changes were made. The images or other third party material in this article are included in the article's Creative Commons licence, unless indicated otherwise in a credit line to the material. If material is not included in the article's Creative Commons licence and your intended use is not permitted by statutory regulation or exceeds the permitted use, you will need to obtain permission directly from the copyright holder. To view a copy of this licence, visit http://creativecommons.org/licenses/by/4.0/.

\section{References}

Burgos, R. B. (2004). Partnership as a floating and empty signifier within educational policies. In B. M. Franklin, M. N. Bloch, \& T. S. Popkewitz (Eds.), Educational partnerships and the state: The paradoxes of governing schools, children, and families. New York: Palgrave Macmillan.

Christophersen, C., (2013) Helper, guard or mediator? Teachers' space for action in The Cultural Rucksack, a Norwegian National Program for arts and culture in schools. International Journal of Education and the Arts, 14, 1:11, 1-17.

Hall, C., \& Thomson, P. (2016). Creativity in teaching: What can teachers learn from artists? Research Papers in Education, 32(1), 106-120.

Hall, C., \& Thomson, P. (2017). Inspiring school change: Transforming education through the creative arts. London: Routledge.

Hanley, B. (2003). The good, the bad, and the ugly - Arts partnerships in Canadian elementary schools. Arts Education Policy Review, 104(6), 11-20.
Hetland, L., Winner, E., Veenema, S., \& Sheridan, K. (2007). Studio thinking: The real benefits of visual arts education. New York: Teachers College Press.

Kenny, A., \& Morrissey, D. (2020). Negotiating teacher-artist identities: "Disturbance" through partnership. Arts Education Policy Review. https://doi.org/10.1080/10632913.2020.1744052.

Neelands, J. (2009). Acting together: Ensemble as a democratic process in art and life. Research in Drama Education: The Journal of Applied Theatre and Performance, 14(2), 173-189.

O’Neill, C. (1995). Drama worlds: A framework for process drama. Pearson Education: University of Michigan.

Perkins, T. (2015). School-community partnerships, friend or foe? The doublespeak of community with educational partnerships. Educational Studies, 51(4), 317-336.

Popkewitz, T. S. (2004). Partnerships, the social pact and changing systems of reason in a comparative perspective. In B. M. Franklin, M. N. Bloch, \& T. S. Popkewitz (Eds.), Educational partnerships and the state: The paradoxes of governing schools, children, and families. New York: Palgrave Macmillan.

Sefton-Green, J. (2011). Creative agents: A review and research project. Newcastle: Creativity, Culture and Education.

Shulman, L. (2005). Signature pedagogies in the professions. Daedalus, 134(Summer), 52-59.

TALE Project Final Report (2019) Time to listen: Evidence from the tracking arts learning and engagement project. Available at https://researchtale.net

Thomson, P., Hall, C., \& Russell, L. (2006). An arts project failed, censored or...? A critical incident approach to artist-school partnerships Changing English vol, 13(1), 29-44.

Thomson, P., Jones, K. \& Hall, C., (2009) Creative whole school change. Final report. London: Creativity, culture and culture and education; Arts Council England.

Thomson, P., Hall, C., Earl, L. \& Geppert, C. (2019) Towards an arts education for cultural citizenship. In S. Riddle \& M.W. Apple (Eds.) Re-imagining Education for Democracy London: Routledge, 174189.

United Nations. (n.d.). Universal declaration of human rights. Article, 27, 1 available at http://www.un.org/en/universal-declaration-humanrights/.

Publisher's note Springer Nature remains neutral with regard to jurisdictional claims in published maps and institutional affiliations. 